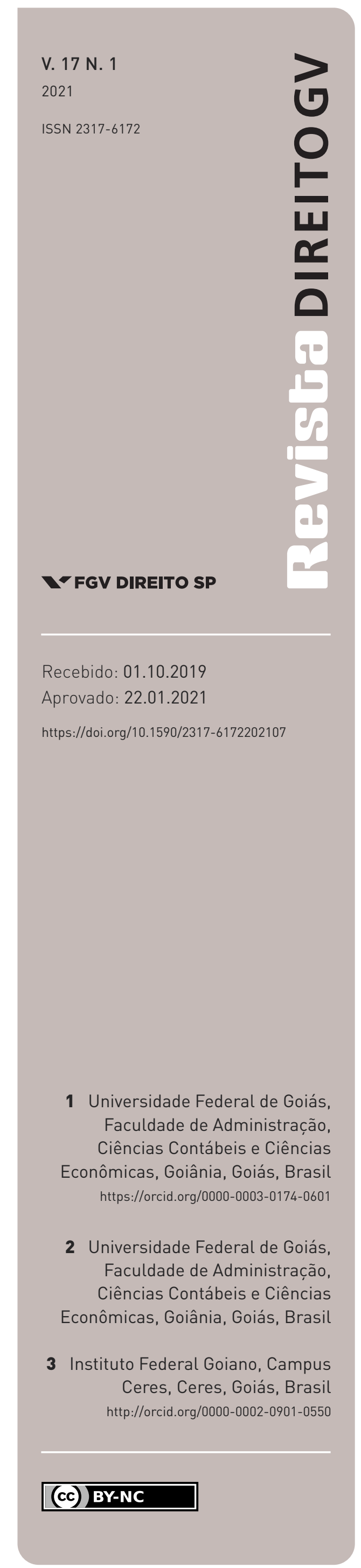

\section{DETERMINANTES QUANTITATIVOS DO DESEMPENHO JUDICIAL: FATORES ASSOCIADOS À PRODUTIVIDADE DOS TRIBUNAIS DE JUSTIÇA}

QUANTITATIVE DETERMINANTS OF JUDICIAL PERFORMANCE: FACTORS ASSOCIATED WITH THE PRODUCTIVITY OF THE COURTS

Renato Máximo Sátiro ${ }^{1}$ e Marcos de Moraes Sousa ${ }^{2,3}$

\section{Resumo}

Muito se tem discutido acerca dos fatores que levariam a uma atuação eficiente ou ineficiente do sistema judiciário brasileiro, e uma parte das discussões acadêmicas em relação ao campo de Administração da Justiça diz respeito aos antecedentes de desempenho/produtividade relativos aos tribunais e magistrados. Nesse sentido, o objetivo principal do presente trabalho foi identificar os aspectos determinantes da produtividade dos tribunais de justiça estaduais no Brasil e testar variáveis emergentes que possam auxiliar nesse entendimento. A partir de uma análise da literatura de referência, foram definidas variáveis já consolidadas: carga de trabalho, quantidade de recursos humanos (servidores efetivos e empregados terceirizados); e variáveis emergentes: advogados e conciliadores. A técnica de inferência utilizada foi a Regressão Múltipla com dados em painel. Após o teste e a validação do modelo e dos pressupostos da Regressão foram confirmadas as hipóteses de que a quantidade de advogados, a carga de trabalho e a quantidade de servidores efetivos e empregados terceirizados afetam a produtividade dos tribunais. Por último, os resultados apontam na direção contrária das orientações do Conselho Nacional de Justiça (CNJ); concluiu-se que a quantidade de conciliadores não está relacionada à produtividade dos tribunais de justiça.

\section{Palavras-chave}

Administração pública; administração da justiça; gestão do Judiciário; desempenho no Judiciário; regressão múltipla.

\section{Abstract}

Much has been discussed about the factors that would lead to an efficient or inefficient performance of the Brazilian Judiciary system, and part of the academic discussions regarding the field of administration of justice concerns the performance/productivity antecedents related to courts and magistrates. In this sense, the main objective of the present work was to identify the determinant aspects of the productivity of the state Courts of Brazil and to test emerging variables that may help in this understanding. From an analysis of the reference literature, the variables already consolidated were defined: workload of the magistrate, amount of human resources (permanent servants and outsourced staff); and the emerging variables: lawyers and conciliators. The inference technique used was the Multiple Regression with panel data. After testing and validating the Regression model and assumptions, the hypothesis that the number of lawyers, the workload and the number of permanent servants and outsourced staff affect the productivity of the courts was confirmed. Finally, the results point in the 
opposite direction of the National Council of Justice (CNJ) guidelines; it was concluded that the number of conciliators is not related to the productivity of the courts.

\section{Keywords}

Public administration; administration of justice; Judiciary management; judicial performance; multiple regression.

\section{INTRODUÇÃO}

Com o advento da Constituição Federal de 1988 (CF/88), a busca do cidadão por serviços judiciais acabou por se intensificar; o sistema judicial brasileiro, que já era considerado lento, tornou-se ainda mais lento com o crescimento do número de processos que chegam ao Judiciário todos os anos (GOMES e FREITAS, 2017).

Em países emergentes, como o Brasil, observa-se que tem crescido continuamente a demanda de processos judiciais (GOMES e GUIMARÃES, 2013); no entanto, a capacidade de resposta do Poder Judiciário não tem acompanhado tal aumento (SADEK, 2004a e 2004b).

Particularmente em relação ao caso brasileiro, observa-se que o Poder Judiciário finalizou o ano de 2018 com 78,7 milhões de processos em tramitação. Em uma análise mais detida, os dados por segmento de justiça demonstram que o resultado global do Judiciário é um reflexo quase direto do desempenho da Justiça estadual, representando esse segmento cerca de $80 \%$ dos processos pendentes na Justiça brasileira (CNJ, 2019). Tal quantidade de processos traz à tona discussões sobre a produtividade judicial e a própria efetividade do Judiciário como um prestador de serviços públicos.

Considerando a importância do Judiciário para a existência do Estado, observa-se que ele tem uma função estruturante na construção da sociedade civil e no que se convencionou chamar de Estado de Direito (GICO JR., 2013); é crucial para a proteção dos direitos formais e para a percepção de justiça por parte dos cidadãos (FALAVIGNA et al., 2015), além de ser um dos atores institucionais relacionados ao desempenho econômico (CHEMIN, 2009; CROSS e DONELSON, 2010) e representar uma instituição essencial para o cidadão (GOMES e FREITAS, 2017).

Nesse sentido, considera-se que a prestação jurisdicional - eficaz, eficiente e efetiva é inerente à própria concepção de democracia, sendo apontada como fator que se associa à própria dignidade da pessoa humana, por vezes alçada à importante condição de direito fundamental (SÁTIRO, 2019).

O Poder Judiciário - em uma democracia - detém a palavra final em relação às instituições, às empresas, às comunidades e aos cidadãos, e tal fato acaba por mobilizar a opinião 
pública (FALCÃO, 2008), deixando ainda mais evidentes os prejuízos de um sistema judicial ineficiente para a coesão do tecido social, bem como para o desenvolvimento econômico (BOTTINI, 2007).

É necessário mencionar ainda o aspecto do empoderamento do Poder Judiciário observado nos últimos anos. Tal aspecto provém de três dimensões: em primeiro lugar, o próprio poder institucional, que compreende o desenho constitucional, bem como as prerrogativas e vedações; em segundo lugar, a judicialização, fator que se dá em virtude do exercício das competências constitucionais, compreendendo ainda a cultura legal e a ampliação dos direitos; em terceiro, o ativismo judiciário, quando o Poder Judiciário passa a interferir no processo decisório, atraindo mais poder para si (BARBOSA, 2015).

Notadamente no caso brasileiro, os sintomas percebidos há longo tempo - crescimento do número de processos, dificuldades de acesso à esfera judicial, duração dos trâmites processuais - são representativos do que se convencionou chamar de "crise do Judiciário"; tais aspectos fazem referência a uma estrutura pesada, sem agilidade, incapaz de propiciar soluções em tempo razoável, previsíveis e a custos acessíveis (SADEK, 2004a). Some-se a tais fatores o comportamento considerado refratário a mudanças, frequentemente apontado em relação aos tribunais brasileiros, bem como a falta de planejamento, apontada como característica das organizações públicas brasileiras (LOURO, SANTOS e ZANQUETTO FILHO, 2017).

Considerando que o Judiciário é custeado por recursos públicos - custando algo em torno de 1,37\% do Produto Interno Bruto (PIB) em 2017, com despesas totais da ordem de R \$ 90,8 bilhões (CNJ, 2018) - e considerando ainda o papel fundamental exercido por esse poder no cotidiano de cidadãos, organizações e países, observa-se que deveria existir ampla prestação de contas à sociedade, permitindo um maior conhecimento do que o Judiciário faz, e como o faz (GOMES e GUIMARÃES, 2013).

Relativamente ao campo da Administração Pública, poucos são os estudos e as pesquisas que têm se ocupado dos aspectos da administração do Judiciário no Brasil (AKUTSU e GUIMARÃES, 2015; ARAGÃO, 1997; GOMES e GUIMARÃES, 2013; LOURO, SANTOS e ZANQUETTO FILHO, 2017; SAUERBRONN e SAUERBRONN, 2015; VIEIRA e PINHEIRO, 2008; VOIGT, 2016), e, apesar do reconhecimento unânime da ineficiência judicial, poucas pesquisas realizam avaliação objetiva e quantitativa desse problema (YEUNG e AZEVEDO, 2012).

Observa-se, ainda, a complexidade da análise de questões relativas ao desempenho das organizações do Judiciário, dado que tais respostas envolvem muitas vezes questões multidimensionais (FALAVIGNA et al., 2015), trazendo consigo conceitos como independência judicial, accountability judicial e efetividade judicial (VOIGT e EL-BIALY, 2016); e esbarram muitas vezes na própria dificuldade de mensurar aspectos que descrevem a eficiência do Judiciário (MITSOPOULOS e PELAGIDIS, 2007); tais fatos podem ser apontados como aspectos que obstam a confecção de pesquisas empíricas que testem os aspectos apontados como antecedentes do desempenho nas organizações judiciárias (LOURO, SANTOS e ZANQUETTO FILHO, 2017). 
Em resposta às lacunas anteriormente apontadas, à pouca literatura relativa ao tema encontrada nos estudos das áreas da Administração e do Direito, bem como às complexidades relativas à investigação quantitativa do desempenho das organizações do Judiciário, a presente pesquisa pretende responder à seguinte questão: quais os aspectos determinantes da produtividade judicial nos tribunais de justiça (TJs) brasileiros? Com o propósito de responder a essa pergunta, o objetivo geral foi identificar as variáveis utilizadas como determinantes da produtividade judicial na literatura de referência, testando empiricamente fatores identificados e não plenamente respondidos pelos estudos anteriores.

\section{A PRODUTIVIDADE JUDiCiAl: A QUANTIFICAÇÃO DA ATIVIDADE JUDICIÁRIA E TEMAS EMERGENTES}

Em todos os níveis do governo, uma das questões centrais colocada em pauta diz respeito à responsabilização pelos serviços colocados à disposição dos usuários; os tribunais não estão imunes a tal constatação (LEWIN, MOREY e COOK, 1982). Desde as reformas em curso na organização e no funcionamento do Estado, que puderam ser observadas nas últimas décadas, pode-se perceber uma tendência mundial na administração pública, qual seja, a adoção de instrumentos de gestão visando à mensuração do desempenho no setor público, com o objetivo de melhorar sua eficiência e seus resultados (NOGUEIRA et al., 2012).

Percebem-se, pelas pesquisas empíricas, relevantes problemas de medição de diversos aspectos que descrevem a eficiência do Judiciário. Os problemas residem não só no aspecto frequentemente encontrado de escassez de dados, mas também na quantificação de medidas intrinsecamente qualitativas, como o próprio conceito de justiça, o que pode acarretar riscos e dificuldades (MITSOPOULOS e PELAGIDIS, 2007).

A despeito de tais dificuldades, observa-se que o Judiciário é tema de estudos que tentam quantificar a "produção de justiça” há algum tempo. Lewin, Morey e Cook (1982), já na década de 1980, ocuparam-se da análise da eficiência administrativa dos tribunais. Em seu estudo, os autores utilizam o método Data Envelopment Analysis (DEA) para a comparação do fator eficiência em uma amostra de cem tribunais superiores militares na Carolina do Norte (EUA). O objetivo dos autores foi demonstrar a aplicação do método para a análise de eficiência aplicada ao Judiciário; eles concluem pela aplicabilidade da técnica e pela viabilidade do estudo de aspectos quantitativos do Judiciário.

Uma das linhas de estudo relativas ao desempenho do Judiciário relaciona-se à tentativa de explicar os determinantes de desempenho, tomando-se como base o Judiciário de determinado país de modo agregado (VOIGT e EL-BIALY, 2016). Uma das variáveis frequentemente utilizadas como antecedentes da produtividade judicial diz respeito à carga de trabalho associada aos tribunais, isto é, à quantidade de processos pendentes de julgamento nos tribunais e sua relação com o quantitativo de magistrados responsáveis pelo acervo de casos, um conceito que também pode ser denominado "estoque de casos per capita". 
Nesse sentido, Jonski e Mankowski (2014) lembram que qualquer sistema judiciário independentemente da tradição legal e do nível econômico associados - é confrontado com um dilema fundamental, qual seja, administrar de modo eficiente a justiça, e muitas vezes sob restrições orçamentárias. Um aspecto crítico associado ao dilema citado pelos autores é o desafio de alocação eficiente desses magistrados em todo o sistema judiciário, de modo a garantir o máximo de eficiência na condução do sistema judiciário.

Beenstock e Haitovsky (2004), nessa mesma linha, analisaram o impacto do número de juízes, bem como a alocação destes para o resultado do sistema judicial. Os autores testaram a hipótese de que os outputs do sistema judiciário seriam incrementados caso houvesse um acréscimo no número de magistrados, ceteris paribus. Os autores avaliaram 25 tribunais israelenses no período de 1964 a 1995, em três diferentes instâncias judiciárias, utilizando dados em painel. As variáveis dependentes foram: casos distribuídos, casos pendentes e número de magistrados. Os autores concluem que o aumento da carga de trabalho impacta positivamente no desempenho, o mesmo não se podendo afirmar acerca do aumento no número de magistrados.

Dimitrova-Grajzl et al. (2012), por sua vez, analisaram como a disponibilidade de recursos humanos no tribunal e o estoque de processos nas cortes da Eslovênia impactam a atividade judicial. Os autores se utilizaram de abordagem econométrica para estimar o impacto das variáveis explicativas no número de casos resolvidos. Eles concluíram que a produção do tribunal não depende estatisticamente do número de juízes em exercício. Em relação à carga de processos, os autores concluem que há evidência estatística suficiente para afirmar que ela impacta positivamente na produção judicial, conforme também conclusão de Beenstock e Haitovsky (2004).

No mesmo sentido, Gomes e Freitas (2017) analisaram a correlação entre a quantidade de magistrados e o desempenho judicial nas varas da Justiça Federal no Brasil, utilizando dados secundários oficiais para a consecução de uma análise de correlação linear entre as variáveis. Os autores concluíram que não há correlação entre a demanda e a quantidade de juízes nas varas estudadas, entretanto há correlação positiva entre a demanda e o desempenho das varas; por fim, concluíram que há correlação negativa entre a quantidade de juízes e o desempenho das varas.

Outro estudo a confirmar a hipótese de que o estoque de processos influencia positivamente o desempenho dos tribunais é o de Sousa e Guimarães (2018), inclusive apontando um impacto aproximadamente sete vezes maior quando comparado aos recursos humanos lotados em cada tribunal.

Nesse sentido, formula-se a primeira hipótese do trabalho.

Hipótese 1: Maior carga de trabalho tem efeito positivo sobre a produtividade dos tribunais. Uma segunda vertente de estudos empíricos aplicados ao Judiciário centra esforços na identificação da relação existente entre a quantidade de funcionários presentes em determinado 
tribunal e a sua relação com o desempenho de magistrados e tribunais; tais estudos partem da premissa de que a disponibilidade de recursos humanos poderia aumentar a quantidade de casos resolvidos.

Mitsopoulos e Pelagidis (2007), utilizando dados em painel, examinaram o tempo necessário para a resolução dos casos nas cortes da Grécia em duas instâncias judiciárias. Os autores chegaram às seguintes conclusões: há um crescimento constante no tempo gasto para a conclusão dos processos, e a razão entre o número de funcionários e o número de casos afeta o tempo de resolução em tribunais de recursos e tribunais superiores; no entanto, tal relação não é verificada em tribunais administrativos de primeira instância. Eles concluíram que a falta de gestão, a quantidade de recursos e os investimentos financeiros realizados afetam negativamente a produtividade do Judiciário.

Resultados semelhantes em relação à quantidade de funcionários foram encontrados por Rosales-López (2008): segundo a autora, há uma relação positiva entre as variáveis relativas aos recursos humanos presentes no tribunal e a quantidade de casos resolvidos; logo, uma maior quantidade de funcionários afeta positivamente a produtividade do tribunal.

O estudo de Louro, Santos e Zanquetto Filho (2017) inova ao tratar da influência do quantitativo de recursos humanos para o desempenho dos tribunais; os autores diferenciam recursos humanos próprios de recursos humanos terceirizados em seu estudo (diferentemente do estudo de Mitsopoulos e Pelagidis [2007] e também do estudo de Gomes e Guimarães [2013]), até mesmo pela característica de organização dos tribunais e da administração pública brasileira, em que convivem servidores efetivos e servidores terceirizados, algo marcante na organização do fator recursos humanos no setor público no Brasil. Louro, Santos e Zanquetto Filho (2017) concluem que o capital humano próprio tem impacto maior no desempenho quando comparado ao capital humano terceirizado.

Nesse sentido, tendo como base o estudo de Louro, Santos e Zanquetto Filho (2017) e considerando a convivência de servidores efetivos e funcionários terceirizados no Poder Judiciário brasileiro, elaboram-se as hipóteses:

Hipótese 2: Maior quantidade de servidores públicos efetivos tem efeito positivo sobre a produtividade dos tribunais.

Hipótese 3: Maior quantidade de funcionários terceirizados tem efeito positivo sobre a produtividade dos tribunais.

Ressalta-se, em relação à Hipótese 2, que o quantitativo de servidores públicos efetivos não inclui o quantitativo de magistrados; a variável constante do relatório Justiça em Números que inclui os magistrados é a força total de trabalho, não sendo o objetivo do presente trabalho debruçar-se especificamente sobre essa questão.

Há que se ressaltar que, embora o número de estudos empíricos aplicados ao Judiciário esteja em crescimento e o tema da produtividade judicial esteja sendo mais discutido 
academicamente, faltam estudos quantitativos sobre algumas relações preconizadas empiricamente, sobretudo do ponto de vista dos fatores que impactam o desempenho judicial.

Um desses fatores diz respeito ao acesso ao Judiciário; sabe-se que a Carta Magna de 1988 ampliou o rol de direitos existentes, positivando uma ampla gama de direitos individuais, trazendo ainda normas relativas aos direitos sociais, bem como um vasto rol de normas programáticas (SADEK, 2004a).

Para o exercício de tais direitos e prerrogativas, a CF/88 elevou a advocacia privada à condição de função essencial à Justiça; nesse sentido, a quase totalidade das ações que serão levadas à apreciação do Poder Judiciário necessita ser impetrada por intermédio da assistência de um advogado. Observa-se que há importantes razões teóricas para acreditar que os advogados podem induzir a litigância (MORA-SANGUINETTI e GAROUPA, 2015).

No entanto, apesar da indisponibilidade da assistência por advogado para a impetração da grande maioria das ações judiciais, não há estudos que caminhem na direção do entendimento da influência dessa função essencial à Justiça em relação aos processos levados à apreciação do Poder Judiciário.

Um dos estudos que tenta preencher tal lacuna é o de Vasconcelos, Watanabe e Netto (2018), que objetivou entender o impacto dos advogados para o resultado de decisões judiciais em casos civis. Os autores analisaram 30.821 decisões prolatadas em ações protagonizadas por 386 advogados federais e concluíram que há diferença significante nas taxas de ganho em metade das 70 equipes pesquisadas no estudo; ainda segundo eles (2018, p. 32), "o fato de os advogados obterem resultados diferentes, apesar de trabalharem no mesmo tipo de caso, indica como as decisões judiciais podem ser afetadas pelo trabalho de um advogado".

Outro estudo que tenta estimar empiricamente o relacionamento entre a quantidade de advogados e a quantidade de litígios é o de Mora-Sanguinetti e Garoupa (2015). No referido estudo, os autores testaram a relação entre o número de advogados e litígios na Espanha, no período de 2001 a 2010, por meio de modelagem econométrica com dados em painel e técnica de estimação por Mínimos Quadrados Ordinários (MQO). Foram construídos dois grupos de variáveis relacionadas a dois fatores: o número de escolas de Direito fundadas no país e a distância entre as atuais capitais das províncias e a capital histórica de seu distrito universitário (onde seria possível estudar Direito). O índice de litígios foi mensurado como a proporção do número de novos processos civis registrados em determinado ano em relação à população. Os resultados encontrados pelos autores permitem concluir que o número de advogados tem efeito positivo na quantidade de litígios.

Considera-se, pelos aspectos expostos, que a assistência advocatícia - seja pela advocacia pública, seja pela privada - seria um fator que poderia impactar a quantidade de processos movidos, bem como a resolubilidade de processos nos tribunais, e nesse sentido formula-se a seguinte hipótese: 
Hipótese 4: Maior quantidade de advogados atuantes no estado tem efeito negativo sobre a produtividade dos tribunais.

Em outra linha de estudos, um dos fatores frequentemente apontados como possível solução para a diminuição da demanda nos tribunais diz respeito aos mecanismos de resolução alternativa de conflitos. O relatório Fazendo com que a justiça conte: medindo e aprimorando o desempenho do judiciário no Brasil, produzido pelo Banco Mundial, já apontava em 2004 a maior difusão do instituto da conciliação como uma possível solução para a excessiva sobrecarga de processos na Justiça Estadual. Segundo o relatório, tal medida poderia ser um importante mecanismo de diminuição das demandas hoje paralisadas no Judiciário estadual (BANCO MUNDIAL, 2004).

Ribeiro (2008), em análise acerca do acesso ao sistema judiciário no Brasil, destaca o papel do CNJ como órgão encarregado de desenvolver ações que visem à redução da morosidade processual e à simplificação dos procedimentos judiciais. A autora destaca, entre as ações desenvolvidas pelo CNJ, a ênfase nos procedimentos alternativos de justiça, entre os quais figura o instituto da conciliação.

Em mesmo sentido, Veronese (2007) realizou análise da evolução de experiências alternativas de resolução de conflitos, descrevendo os projetos e as questões políticas implicadas nesse fenômeno. Segundo o autor, apesar do consenso em relação à inserção do Brasil em um contexto de tradição jurídica formalista, ocorre atualmente um movimento descrito como "permeabilidade às novas referências institucionais para a solução dos conflitos e ao discurso de intervenção social”, agenda que, segundo Veronese (2007, p. 19), vem se desenvolvendo de modo célere no Brasil. Um exemplo citado por ele diz respeito à realização do "Dia Nacional da Conciliação", evento promovido pelo CNJ com o intuito de difundir entre os tribunais a cultura da realização de acordos entre os litigantes com vistas a extinguir demandas judiciárias.

Nesse sentido, considerando que os meios alternativos poderiam solucionar conflitos e diminuir o número de processos que estão hoje pendentes de julgamento no Poder Judiciário, cita-se a última hipótese do presente trabalho:

Hipótese 5: Maior quantidade de conciliadores tem efeito positivo sobre a produtividade dos tribunais. Akutsu e Guimarães (2012) enfatizam que o desempenho e a produtividade dos tribunais podem ser mensurados mediante diversos indicadores, quais sejam: tempo de julgamento, custo do processo e qualidade da sentença. O CNJ, por sua vez, por intermédio da publicação do relatório Justiça em Números, trata o desempenho como o número de processos baixados (LOURO, SANTOS e ZANQUETTO FILHO, 2017); no presente trabalho é utilizado o número de casos resolvidos por magistrado por ano como indicador de produtividade.

Há que se ressaltar que tal variável busca equacionar a heterogeneidade existente entre os TJs no Brasil, havendo tribunais de pequeno, médio e grande porte. Um dado ilustrativo dessa questão mostra que, em média, no ano de 2018, a cada grupo de 100 mil habitantes, 11.796 
ingressaram com uma ação judicial. Especificamente em relação à Justiça estadual, o tribunal mais demandado é o TJ do Distrito Federal e dos Territórios (12.154) e o menos demandado é o TJ do Pará (2.799) (CNJ, 2019).

Ainda no que concerne à operacionalização da variável produtividade dos tribunais, observa-se que, em detrimento da crítica acerca da discussão sobre a complexidade dos casos distribuídos aos magistrados - o que acabaria por afetar diretamente o resultado de determinado magistrado, de modo que juízes que julgassem casos menos complexos seriam mais produtivos (GOMES, ALVES e SILVA, 2018a) -, registra-se que a distribuição aleatória dos casos aos magistrados no país (GICO JR., 2013) tende a reduzir a discrepância na complexidade do rol de casos distribuídos a cada magistrado (GOMES, ALVES e SILVA, 2018a). Tais observações são, segundo Gomes, Alves e Silva (2018a), justificativas ao uso dos indicadores agregados de produtividade dos tribunais, pois refletem o efeito sistêmico da aleatoriedade e do equilíbrio estrutural da distribuição dos processos.

\section{MÉTOdo}

Conforme o objetivo e as variáveis da presente pesquisa, a técnica escolhida foi a Regressão Múltipla com dados em painel. A fim de verificar o efeito das variáveis identificadas na literatura para o desempenho dos tribunais - conceito operacionalizado por meio da produtividade dos magistrados dos TJs - , foi utilizado um modelo econométrico de Regressão Múltipla com análise de dados em painel, haja vista o fato de terem sido coletados dados dos anos de 2011 a 2019, em um total de 243 observações. Em princípio, tais dados não receberam tratamento adicional além do tratamento das observações perdidas.

Foram utilizados dados secundários, obtidos por meio do relatório Justiça em Números, organizado e publicado com periodicidade anual pelo CNJ e disponibilizado no sítio eletrônico do próprio órgão (CNJ, 2017). Tal relatório é publicado desde 2003 e constitui-se na principal fonte de dados e estatísticas referentes ao Poder Judiciário no Brasil.

Os dados relativos aos advogados foram coletados mediante duas ferramentas de guarda e disponibilização de versões antigas de sites hospedados na internet (Wayback Machine e Oldweb). Foram buscadas as versões antigas do site do Conselho Federal da Ordem dos Advogados do Brasil (OAB); a OAB divulga em seu sítio eletrônico o quantitativo de advogados inscritos nas 27 seccionais brasileiras. Tais dados são atualizados com periodicidade diária. Ressalta-se que, em razão de não haver disponibilidade de todas as datas de todos os anos nessas ferramentas de pesquisa, foi utilizado o dia mais próximo da data de 31 de dezembro do ano pretendido na análise, como indicador do quantitativo de advogados de determinado ano.

A variável dependente $(\mathrm{Y})$ do estudo é a produtividade dos tribunais, obtida por meio da quantidade de processos baixados no tribunal por ano dividida pela quantidade de juízes que atuam no tribunal, conforme estudo de Gomes, Alves e Silva (2018b). Tal divisão busca equacionar as discrepâncias de tamanho dos diferentes TJs existentes no país. 
Foram utilizadas as seguintes variáveis explicativas: (i) carga de trabalho: quantidade de processos pendentes de julgamento no tribunal no período dividida pela quantidade de juízes que atuam no tribunal; (ii) quantidade de servidores efetivos: quantidade de servidores integrantes do quadro efetivo dos tribunais; (iii) quantidade de funcionários terceirizados: quantidade de empregados contratados mediante processo de terceirização; (iv) quantidade de advogados: quantidade de advogados atuantes no estado ao final do exercício do ano corrente; e (v) quantidade de conciliadores: quantidade de conciliadores que atuam no estado referente a determinado tribunal.

Seguindo orientação de Gomes, Alves e Silva (2018b), as variáveis explicativas foram divididas pelo quantitativo de magistrados, de modo a evitar discrepâncias em relação aos diferentes portes dos tribunais, uma vez que, segundo os autores, a amostra consiste em tribunais heterogêneos. Tal técnica foi utilizada no presente trabalho, resultando em números que serão descritos na seção de resultados relativos às estatísticas descritivas.

A aplicação das técnicas estatísticas foi feita com o auxílio de dois softwares gratuitos: o software R, por meio da interface R-Studio, versão 3.4.1 (2017-06-30), e o software Gretl, em sua versão gretl 1.9.14.

Observa-se que as rotinas estatísticas relativas à análise de pressupostos e a escolha do melhor modelo de estimação de dados em painel encontram-se detalhadas em apêndice metodológico, apresentado ao final do presente artigo. Desse modo, passa-se agora à apresentação, análise e discussão dos resultados.

\section{Resultados}

\section{I. ESTATÍSTICAS DESCRITIVAS}

A Tabela 1 refere-se às estatísticas descritivas da variável dependente e das variáveis independentes. Observa-se que a quantidade de processos baixados por magistrado (a produtividade) apresenta grande variabilidade, assumindo valores que vão de 964,77 a 3.132,10, com uma média de 1.883 processos. Nota-se grande variabilidade no número de decisões proferidas anualmente pelos juízes dos diversos TJs, o que pode indicar que um ou mais fatores seriam os responsáveis por essa grande discrepância na quantidade de processos baixados. 
TABELA 1 - ESTATÍSTICAS DESCRITIVAS

\begin{tabular}{|c|c|c|c|c|c|c|}
\hline & PRODUTIVIDADE & SERVIDORES & TERCEIRIZADOS & CONCILIADORES & $\begin{array}{l}\text { CARGA DE } \\
\text { TRABALHO }\end{array}$ & ADVOGADOS \\
\hline MÍNIMO & 964,77 & 7,56 & 0 & 0 & 978,87 & 11,98 \\
\hline MEDIANA & 1868,10 & 15,43 & 3,09 & 0,41 & 3200,30 & 53,00 \\
\hline MÉDIA & 1860,10 & 15,64 & 3,20 & 0,58 & 3708,80 & 60,16 \\
\hline MÁXIMO & 3132,10 & 28,93 & 8,15 & 3,61 & 14215 & 180,85 \\
\hline INTERVALO & 2167,33 & 21,37 & 8,15 & 3,61 & 13236,13 & 168,87 \\
\hline DESVIO PADRÃO & 361,95 & 3,67 & 1,52 & 0,69 & 2333,60 & 31,51 \\
\hline $\begin{array}{l}\text { COEFICIENTE } \\
\text { DE VARIAÇÃO }\end{array}$ & 0,19 & 0,23 & 0,47 & 1,18 & 0,63 & 0,52 \\
\hline NA'S & 0 & 0 & 5 & 1 & 0 & 0 \\
\hline CONTAGEM & 243 & 243 & 243 & 243 & 243 & 243 \\
\hline
\end{tabular}

Fonte: Dados da pesquisa.

O quantitativo total de servidores apresenta números que vão desde 7,56 até 28,93 servidores por magistrado. Observa-se nessa variável uma grande variação no quantitativo de servidores por magistrado, com média de 15,64 e desvio padrão de 3,67. Ressalta-se que o TJ de São Paulo detinha o maior quantitativo de servidores no ano de 2019, com um total de 41.633 servidores por magistrado, em contraste com o TJ de Roraima, com um total de 891 servidores.

O número de empregados terceirizados assume valores entre 0 e 8,15 empregados por magistrado, com desvio padrão de 1,52 e média de 3,20. Pode-se observar nessa variável que há ao menos um TJ que em determinado ano não tinha nenhum empregado terceirizado, enquanto outro TJ tinha mais de oito empregados terceirizados por magistrado. O quantitativo de empregados terceirizados encontra seus extremos nos TJs de São Paulo e do Amazonas, maior e menor valor, respectivamente, possuindo o primeiro 9.553 servidores terceirizados por juiz e o segundo 71 servidores terceirizados no ano de 2019.

A quantidade de conciliadores por magistrado vai de 0 até um total de 3,61 conciliadores por magistrado, sendo a média de 0,58 e o desvio padrão de 0,69. Do mesmo modo que o número de empregados terceirizados, há algum TJ que em algum ano não possuía nenhum conciliador em seus quadros, enquanto na outra ponta haveria um TJ que marcava em seus quadros 
mais de 3 conciliadores por magistrado. A título de exemplo, o TJ de São Paulo apresenta o maior quantitativo de conciliadores por magistrado, 4.301, enquanto os TJs do Amazonas, de Rondônia, de Tocantins, de Sergipe e do Maranhão não apresentavam nenhum conciliador em seus quadros no ano de 2019.

A carga de trabalho (operacionalizada por intermédio do número de casos pendentes de julgamento por magistrado) assume valores de 978,87 a 14.215 processos, com valores de desvio padrão e média de 2.333,60 e 3.708,80, respectivamente. Nessa variável em questão, observa-se uma das maiores discrepâncias entre os valores mínimo e máximo, sendo o valor máximo mais de catorze vezes o quantitativo do valor mínimo, denotando uma enorme variabilidade no quantitativo de casos pendentes entre os diversos tribunais nos estados. O estado com maior estoque de casos por magistrado é o estado de São Paulo, 19.138.363 processos per capita, e Roraima é o estado com o menor estoque de processo per capita, com 58.851 casos por magistrado no ano de 2019.

A variável relativa ao número de advogados inscritos em cada seccional apresenta valores que vão de 11,98 a 180,85, com média e desvio padrão de 60,16 e 31,51. Tal amplitude observada entre os valores mínimo e máximo é explicada, em parte, em virtude da própria evolução no número de faculdades de Direito existentes no país (MOURA, COSTA e MENDONÇA, 2012), que, por sua vez, acarreta um maior número de concluintes do curso ao longo dos últimos anos. Mais uma vez, o estado de São Paulo apresenta o maior quantitativo, um total de 318.419 advogados por magistrado, e Roraima, com 2.101 advogados por magistrado, o menor número.

Fora realizada na presente pesquisa análise para a identificação de dados faltantes; foram identificados cinco dados faltantes para a varável "terceirizados" (tribunais da Bahia e do Espírito Santo nos anos de 2011 e 2012 e tribunal da Paraíba em 2011) e um dado faltante para a variável "conciliadores" (tribunal do Amazonas, em 2017), sendo identificados ao todo seis dados faltantes para a amostra objeto da presente pesquisa. Tais dados foram substituídos pela média de cada variável, de modo a atribuir um valor a partir do raciocínio de que a média do conjunto de dados é o valor único mais adequado para essa substituição (FÁVERO et al., 2009).

A matriz de correlação, apresentada pela Tabela 2, evidencia a análise bivariada, ou seja, a medida do relacionamento entre as variáveis tomadas duas a duas. 
TABELA 2 - MATRiZ DE CORRELAÇÃo

CARGA DE

PRODUTIVIDADE SERVIDORES TERCEIRIZADOS CONCILIADORES ADVOGADOS TRABALHO

\begin{tabular}{|c|c|c|c|c|c|c|}
\hline PRODUTIVIDADE & 1 & & & & & \\
\hline SERVIDORES & 0,08 & 1 & & & & \\
\hline TERCEIRIZADOS & $0,44^{* * *}$ & $0,23^{* * *}$ & 1 & & & \\
\hline CONCILIADORES & 0,24 & 0,24 & $0,35^{* * *}$ & 1 & & \\
\hline ADVOGADOS & $0,5^{* * *}$ & 0,07 & $0,54^{* * *}$ & $0,62^{* * *}$ & 1 & \\
\hline $\begin{array}{l}\text { CARGA DE } \\
\text { TRABALHO }\end{array}$ & $0,76^{* * *}$ & $0,00^{* * *}$ & $0,35^{* * *}$ & $0,49^{* * *}$ & $0,77^{* * *}$ & 1 \\
\hline
\end{tabular}

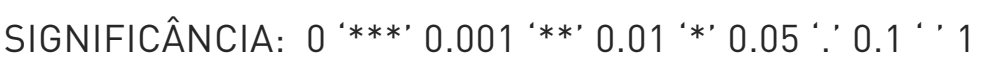

Fonte: Elaborada pelos autores.

3.2. RESULTADOS DA REGRESSÃO: SIGNIFICÂNCIA DO MODELO E DAS VARIÁVEIS EXPLICATIVAS

A Tabela 3 mostra os resultados da Regressão Múltipla com dados em painel. Observa-se por ela que as variáveis "servidores", "terceirizados", "quantidade de advogados" e "carga de trabalho" são significantes; e a variável: “conciliadores” não se mostra significante para o modelo proposto.

Tal resultado mostra que as variáveis estatisticamente significantes são representativas da variação observada na variável dependente. Ou seja, as variáveis descritas (com exceção do quantitativo de conciliadores) são fatores que podem explicar uma parcela da variação na produtividade dos tribunais.

Pela interpretação dos coeficientes da Regressão Múltipla com dados em painel, observase que para cada servidor que seja alocado em determinado tribunal haverá um incremento de 55 unidades na variável preditora, ou seja, a cada servidor disponibilizado será aumentado em 55 unidades o quantitativo de processos baixados por juiz por ano naquele tribunal.

Interpretação semelhante pode ser feita em relação aos servidores terceirizados, aos conciliadores e à carga de trabalho. Aumentando-se uma unidade em cada uma das variáveis descritas, os processos baixados por magistrado por ano, ceteris paribus, serão incrementados em uma magnitude de, respectivamente, 23,75, 9,34 e 0,16 processos por magistrado. Ressalta-se que a variável relativa ao quantitativo de conciliadores não se mostrou estatisticamente significante, não podendo ser utilizada para a confecção desse tipo de análise. 
A relação entre carga de trabalho e produtividade é descrita pela literatura como a “produtividade exógena” dos magistrados. A aparente contradição de, havendo maior estoque de casos, haver mais produtividade é documentada pela literatura e confirmada pelo presente estudo.

Observa-se ainda que a única variável com efeito inverso em relação à produtividade é a variável relativa ao quantitativo de advogados. Para cada uma unidade aumentada em relação a essa variável, ceteris paribus, espera-se um decréscimo de produtividade da ordem de 1,86 processo por magistrado por ano.

TABELA 3 - RESULTADOS DA REGRESSÃO MÚLTIPLA COM DADOS EM PAINEL

\begin{tabular}{lllll} 
& COEFICIENTE & ERRO PADRÃO & RAZÃO-T & P-VALOR \\
\hline CONSTANTE & 417,39 & 119,35 & 3,49 & 0,0006 \\
\hline SERVIDORES & 55,67 & 7,16 & 7,78 & $3,26 E-013$ \\
\hline TERCEIRIZADOS & 23,75 & 14,19 & 1,67 & 0,0956 \\
\hline CONCILIADORES & 9,34 & 30,98 & 0,30 & 0,7633 \\
\hline ADVOGADOS & $-1,86$ & 0,89 & $-2,09$ & 0,0381 \\
\hline CARGA DE TRABALHO & 0,16 & 0,02 & 9,92 & $2,76 \mathrm{E}-019$ \\
\hline
\end{tabular}

R2: 0,8388

P-VALOR: 3,37E-67

$F(31,211): 35,42516$

SIGNIFICÂNCIA: 0 “***’ $0.001^{\prime * * *} 0.01^{\prime *} * 0.05$ ' 0.1 ' 1

INCLUÍDAS 27 UNIDADES DE CORTE TRANSVERSAL

COMPRIMENTO DA SÉRIE TEMPORAL = 9

VARIÁVEL DEPENDENTE: PRODUTIVIDADE

Fonte: Dados da pesquisa.

Por intermédio da Tabela 3, pode-se depreender que a parcela explicada pelo modelo da variação da variável dependente "produtividade" é de aproximadamente 83,88\%. Ou seja, a partir das variáveis incluídas no modelo, pode-se explicar 83,88\% da variação da produtividade dos TJs. 
Desse modo, após os testes estatísticos realizados, as conclusões relativas às hipóteses iniciais do estudo são apresentadas no Quadro 1, a seguir.

QUADRO 1 - RESUMO DAS HIPÓTESES E SEUS RESULTADOS

HIPÓTESE DESCRIC̣ÃO

$$
\mathrm{H} 1
$$

H

$\mathrm{H} 2$

EFE

$$
\text { H3 }
$$

H4

4

H5

\section{RESULTADO}

NÃO REJEITADA

(SUPORTADA)

NÃO REJEITADA

(SUPORTADA)

NÃO REJEITADA

(SUPORTADA)

NÃO REJEITADA

(SUPORTADA)

REJEITADA

(NÃO SIGNIFICANTE)

Fonte: Dados da pesquisa.

\section{Discussão dos ReSUltados}

Observou-se pela revisão da literatura que uma das grandes preocupações em relação à quantificação da produtividade do Judiciário está centrada em encontrar os fatores determinantes dessa produtividade. Ou seja, em grande parte dos estudos analisados para a confecção da presente pesquisa, a preocupação está em encontrar e quantificar a influência de determinados fatores para o desempenho dos magistrados e tribunais. Observa-se ainda que grande parte desses estudos está focada na obtenção das variáveis que melhor explicariam a produtividade judiciária.

Em relação à parte metodológica, observou-se que uma parcela desses estudos se utiliza do método DEA para a análise do desempenho judicial. A escolha de tal método provavelmente se dê pela sua natureza, sendo tal análise empregada como um método de análise de eficiência, bem como pela sua característica de estabelecer indicadores de avaliação da eficiência ao considerar a relação inputs/outputs das organizações objeto de estudo.

A análise de alguns dos indicadores no presente trabalho, especificamente em relação aos atores envolvidos no processo - servidores (efetivos e terceirizados), advogados e conciliadores; 
e ainda a carga de trabalho associada a cada tribunal - foi operacionalizada mediante a técnica de Regressão Múltipla, utilizando a abordagem de dados em painel.

Os resultados relativos aos servidores efetivos e funcionários terceirizados corroboram os resultados encontrados por Mitsopoulos e Pelagidis (2007) e Louro, Santos e Zanquetto Filho (2017). No entanto, uma particularidade do estudo de Louro, Santos e Zanquetto Filho (2017) é o fato de os autores dividirem as duas espécies de funcionários e concluírem que elas são estatisticamente significantes para explicar a produtividade judicial; nesse sentido, observa-se que uma grande peculiaridade do caso brasileiro reside na convivência entre funcionários terceirizados e servidores efetivos; sendo, assim, relevante a quantificação dos resultados relativos ao fenômeno da terceirização das relações de trabalho, terceirização essa que tem crescido tanto na esfera privada quanto na esfera pública. O presente estudo encontrou resultados congruentes com o estudo de Louro, Santos e Zanquetto Filho (2017).

Nesse sentido, observa-se que a quantidade de pessoas envolvidas nos processos relacionados às atividades desempenhadas pelo Judiciário é fator de atenção e de importância quando se fala em desempenho e produtividade judicial, ou seja, a quantidade de pessoas lotadas em determinado TJ é um dos fatores que auxiliam na compreensão do quantitativo de processos julgados por magistrado da justiça estadual. Tal fato deve ser mais bem compreendido a fim de auxiliar nas políticas de administração de recursos humanos do Poder Judiciário, de modo a alocar o quantitativo que melhor se preste à boa consecução dos seus trabalhos.

Com relação aos advogados, muito se tem falado sobre o crescimento do número de faculdades de Direito no país (MOURA, COSTA e MENDONÇA, 2012), existindo algo em torno de 1.303 cursos de Direito no país, com um total de aproximadamente 880 mil alunos matriculados no ano de 2018, segundo o Censo da Educação Superior (INEP, 2019). Nesse sentido, muito se ventila em relação ao crescente quantitativo de bacharéis formados no país, já que grande parte destes opta pela carreira da advocacia, e aumenta, por conseguinte, o número de advogados per capita no Brasil. Torna-se necessário investigar as consequências que tal número acarreta para o sistema judiciário como um todo, pois, conforme a CF/88, a advocacia é uma das funções essenciais à Justiça.

Nesse sentido, o presente trabalho se propôs a realizar a investigação da influência do número desses profissionais para a produtividade judicial, partindo da ideia de que o aumento deles poderia, de algum modo, afetar o número de processos judiciais em curso no país a demanda de processos judiciais - e, por consequência, ter algum efeito sobre a produtividade dos tribunais estaduais, que carregam o maior acervo de processos em todas as especializações judiciárias.

Pelas análises estatísticas realizadas, encontram-se evidências suficientes para concluir que o número de advogados atuando em determinada seccional da OAB exerce algum tipo de influência sobre a produtividade dos TJs dessa seção, ou seja, para a justiça estadual brasileira, o quantitativo de advogados atuando em determinada seccional da OAB é fator que poderia explicar a produtividade judicial. 
Já em relação aos conciliadores, observa-se que o quantitativo destes não foi estatisticamente significante para a produtividade judicial de determinado tribunal. Nesse sentido, por intermédio dos resultados encontrados no presente estudo, não se pode afirmar que os diversos esforços do CNJ em implementar reformas que reforcem as atividades de conciliação no âmbito do Poder Judiciário têm surtido o efeito desejado. Observa-se que, também a partir dos resultados observados pelo estudo, essas ações de fomento ao instituto da conciliação no Brasil (que a princípio seriam de auxílio para aumentar o desempenho do Poder Judiciário, considerando que tais ações teriam o condão de dar resolubilidade às demandas que antes inevitavelmente iriam desaguar no já grande acervo de processos submetidos à apreciação do Poder Judiciário) não têm resultado em uma relação linear positiva, ou seja, não foi encontrada evidência no presente estudo de que o aumento do número de conciliadores tem resultado em aumento de produtividade dos TJs até o presente momento.

Tal constatação decorre provavelmente de a hipótese referente à carga de trabalho estar positivamente relacionada à produtividade judicial, ou seja, o processo de conciliação que tem a prerrogativa de desafogar o Judiciário, diminuindo o estoque de processos que estão à espera de apreciação pelo Poder Judiciário - acaba por não influenciar a produtividade dos magistrados, fato provavelmente ligado à hipótese da chamada "produtividade exógena” dos magistrados.

Conforme os estudos de Beenstock e Haitovsky (2004) e Dimitrova-Grajzl et al. (2012), observa-se que a carga de trabalho é fator relacionado à quantidade de processos julgados pelos magistrados, ou seja, quanto mais processos pendentes de julgamento em determinado TJ, mais processos seriam julgados em contrapartida pelos magistrados atuando em determinado tribunal. Entretanto, Jonski e Mankowski (2014), Gomes, Alves e Silva (2018b) e Gomes, Guimarães e Akutsu (2017) lembram que a hipótese relativa à "produtividade exógena” dos magistrados tem sido criticada por uma suposição errônea de uma linearidade na relação entre processos pendentes de julgamento e magistrados. Tal constatação poderia passar a impressão de que essa relação seria mantida ad eternum e que poderia continuar aumentando indefinidamente, o que não é o caso. Conquanto, apesar das críticas, a relação tem sido confirmada ao longo dos estudos anteriores (BEENSTOCK e HAITOVSKY, 2004; DIMITROVA-GRAJZL et al., 2012), do mesmo modo, no presente estudo há evidência estatística suficiente para apoiar tal hipótese.

A despeito das críticas relativas à hipótese da produtividade exógena dos magistrados, o que parece ser de grande validade empírica é a ideia de que mais magistrados significariam mais processos julgados, pois, como se tem percebido pelos estudos anteriores, apesar de não ser possível afirmar que a quantidade de processos pendentes de julgamento traria mais produtividade indefinidamente, algumas considerações acerca do processo inverso podem ser feitas; pode-se afirmar, por exemplo, que a simples colocação de mais magistrados em atuação em determinado tribunal não seria garantia de maior produtividade nesse tribunal. 
Muito embora não seja pretensão do presente trabalho elaborar um modelo preditivo ou explicativo das variáveis do desempenho judicial, salienta-se que o modelo proposto tem boa explicação da variável dependente, conseguindo abranger cerca de 83,88\% da variação relativa ao desempenho observado nos TJs pesquisados.

\section{CONSIDERAÇÕES FINAIS}

Tendo em vista a relevância da Justiça para o desenvolvimento de toda e qualquer sociedade, bem como as prerrogativas associadas ao Poder Judiciário - de dizer o Direito de forma definitiva, tendo para tanto o monopólio da atividade jurisdicional do Estado -, observa-se a importância de se estudar "o que o Judiciário faz e como o faz".

Considerando o cenário atual de crescimento do acesso por parte dos cidadãos ao Poder Judiciário, bem como o estoque de casos pendentes de julgamento e ainda a cultura de judicialização associada ao contexto brasileiro, percebe-se que a tendência de crescimento no número de processos levados à apreciação do Poder Judiciário não parece evoluir para um cenário de queda nos próximos anos.

A despeito das medidas adotadas nos últimos anos com vistas à reforma do Judiciário e de todas as iniciativas para aumentar a eficiência e a celeridade no julgamento dos processos judiciais, o que se observa é que o cidadão continua - em muitos casos - privado do seu direito constitucionalmente assegurado da razoável duração de seu processo; não raro, ele se vê prejudicado em seus interesses jurídicos em razão da demora do sistema judiciário em dar solução aos mais diversos casos levados à apreciação.

O presente trabalho visou contribuir com o entendimento de um campo pouco estudado na área da Administração Pública e do Direito, a produtividade do Poder Judiciário. Para tanto, buscou aprofundar o entendimento do relacionamento entre as variáveis explicativas da produtividade judicial e da relação entre algumas variáveis explicativas e o desempenho judicial; no entanto, nota-se que, por mais esforços que sejam envidados nesse sentido, consegue-se explicar apenas uma parte do fenômeno - fenômeno esse multidisciplinar - e lançar luz sobre algumas poucas relações pertinentes ao tema.

Considera-se que ainda há muito por explicar das complexas relações referentes ao desempenho judicial, e, nesse sentido, recomendam-se estudos futuros que auxiliem na compreensão do papel dos advogados e dos defensores públicos na conclusão dos processos, de modo a entender o papel deles para o sistema judiciário e como a quantidade desses profissionais - e o consequente maior acesso ao Judiciário - tem sido fator de impacto na quantidade de processos que chegam ao Judiciário todos os anos.

Do mesmo modo, observa-se que ainda há poucas informações relativas ao papel da quantidade de conciliadores em atuação no quantitativo de casos que chegam à apreciação judicial; sugerem-se pesquisas que expliquem melhor essa relação, abordando o tema de forma qualitativa e quantitativa, entendendo quais processos se prestam mais à conciliação e quais as con- 
sequências em termos de custo, mobilização de pessoal, tempo despendido, entre outros fatores envolvidos na decisão de deixar de promover determinada lide judicial e, consequentemente, optar pela resolução por via conciliatória.

Propõem-se ainda como agenda de pesquisas futuras estudos detalhados das diferenças entre os tribunais, entre as entrâncias e entre os quadros respectivos de servidores em seus diferentes status, por exemplo, requeridos, estagiários, entre outros. Sabendo que há diferenças no desempenho de determinados tribunais - e no desempenho dos magistrados componentes do quadro desse tribunal -, propõe-se que sejam realizadas pesquisas qualitativas e quantitativas de modo a oferecer respostas à questão: Por que determinado tribunal responde melhor à intensificação de investimentos em contratação de pessoal? E assim poderia ser feito com uma infinidade de outras variáveis presentes no relatório Justiça em Números; tal pergunta poderia ser um incentivo à descoberta dos fatores influenciadores de determinadas relações. Tais relações adotam um padrão linear em algumas técnicas quantitativas de análise, mas tal relação nem sempre nos oferece a dimensão de como determinado tribunal responde a determinado estímulo, e muito menos o porquê de essas diferenças existirem (quando elas existem).

Como limitações do estudo, podem-se citar os fatores relativos à obtenção dos dados presentes nas análises do trabalho. Apesar do enorme salto na disponibilização de dados e estatísticas promovido pelo advento do relatório Justiça em Números, do CNJ, observa-se que algumas variáveis ainda contam com um expressivo número de dados perdidos, fator que acaba por dificultar algumas análises estatísticas, inviabilizando a utilização de técnicas estatísticas que se poderiam prestar - ou se combinar - para melhor explicar determinado fenômeno.

Outra limitação reside no fato de o campo de pesquisas referentes ao desempenho judiciário ser ainda um campo em construção, tendo poucas relações empíricas plenamente explicadas pela literatura de referência; desse modo, há poucas hipóteses de pesquisa que possam ser utilizadas para a formulação de novas hipóteses concernentes aos fatores que poderiam explicar o desempenho de tribunais e magistrados.

Por fim, conforme Procopiuck (2018), registra-se que estratégias gerenciais e tecnológicas que impactam diretamente os processos judiciais por si sós não encerram toda a complexidade do desempenho judicial e do processo judicial, não podendo ser utilizadas de modo isolado para explicar tal fenômeno; diversos outros fatores devem ser considerados nessa equação, tais como a legislação que estipula prazos e a quantidade de recursos admitidos.

Por conseguinte, ainda segundo Procopiuck (2018), considera-se que a eficiência e a eficácia de procedimentos legais também são em grande medida influenciadas por regulamentações legais que estão fora do campo da Administração. E, embora reconhecendo que tais dificuldades não possam ser utilizadas como subterfúgio que obstaculize a pesquisa acerca do desempenho judicial, salientam-se as dificuldades inerentes ao próprio sistema judiciário como um fator de complicação quando da confecção de pesquisas que tenham como temática o desempenho judicial. 


\section{AGRADECIMENTOS}

Os autores agradecem o apoio financeiro da Coordenação de Aperfeiçoamento de Pessoal de Nivel Superior (Capes) pela bolsa do primeiro autor e do Conselho Nacional de Desenvolvimento Científico e Tecnológico (CNPq) em projeto $(404709 / 2018-4)$.

\section{REFERÊNCIAS}

AKUTSU, Luiz; GUIMARÃES, Tomás de Aquino. Governança judicial: proposta de modelo teórico-metodológico. Revista de Administração Pública, v. 49, n. 4, p. 937-958, 2015.

AKUTSU, Luiz; GUIMARÃES, Tomás de Aquino. Dimensões da governança judicial e sua aplicação ao sistema judicial brasileiro. Revista Direito GV, v. 8, n. 1, p. 183-202, 2012.

ARAGÃO, Cecília Vescovi de. Fatores agilizadores e restritivos à atuação da justiça do trabalho: um estudo exploratório. Revista de Administração Pública, v. 31, n. 4, p. 183-215, 1997.

BAIGORRI, Maria Camila. Securitização de recebíveis e risk taking das instituições financeiras: evidências do mercado brasileiro. 2014. Dissertação (Mestrado) - Faculdade de Economia, Administração e Ciências Contábeis e Atuariais - FACE. Programa Multi-institucional e Inter-Regional de Pós-graduação em Ciências Contábeis, UnB/UFPB/UFRN, Brasília, 2014.

BANCO MUNDIAL. Fazendo com que a justiça conte: medindo e aprimorando o desempenho do judiciário no Brasil. Relatório n. 32789, Banco Mundial, Washington, DC, 2004.

BARBOSA, Leon Victor de Queiroz. O silêncio dos incumbentes: fragmentação partidária e empoderamento judicial no Brasil. 2015. Tese (Doutorado) - Programa de Pós-graduação em Ciência Política, Universidade Federal de Pernambuco, Recife, 2015.

BEENSTOCK, Michael; HAITOVSKY, Yoel. Does the appointment of judges increase the output of the judiciary? International Review of Law and Economics, v. 24, n. 3, p. 351-369, 2004.

BOTTINI, Pierpaolo Cruz. A reforma do Judiciário: aspectos relevantes. Revista da Escola Nacional de Magistratura, v. 2, n. 3, p. 89-99, 2007.

BROOKS, Chris. Introductory econometrics for finance. 3. ed. Cambridge: Cambridge University Press, 2014. 
CHEMIN, Matthieu. Do judiciaries matter for development? Evidence from India. Journal of Comparative Economics, v. 37, n. 2, p. 230-250, 2009.

CONSELHO NACIONAL DE JUSTIÇA (CNJ). Justiça em Números 2019: ano base 2018. Brasília: Conselho Nacional de Justiça, 2020.

CONSELHO NACIONAL DE JUSTIÇA (CNJ). Justiça em Números 2018: ano-base 2017. Brasília: Conselho Nacional de Justiça, 2019.

CONSELHO NACIONAL DE JUSTIÇA (CNJ). Justiça em Números 2017: ano-base 2016. Brasília: Conselho Nacional de Justiça, 2018.

CROSS, Frank B.; DONELSON, Dain C. Creating quality courts. Journal of Empirical Legal Studies, v. 7, n. 3, p. 490-510, 2010.

DIMITROVA-GRAJZL, Valentina et al. Court output, judicial staffing, and the demand for court services: evidence from Slovenian courts of first instance. International Review of Law and Economics, v. 32, n. 1, p. 19-29, 2012.

FALAVIGNA, Greta et al. Judicial productivity, delay and efficiency: A Directional Distance Function (DDF) approach. European Journal of Operational Research, v. 240, n. 2, p. 592-601, 2015.

FALCÃO, Joaquim. Uma reforma muito além do Judiciário. Revista do Curso de Mestrado em Direito da UFC, v. 28, n. 2, p. 251-262, 2008.

FÁVERO, Luiz Paulo et al. Análise de dados: modelagem multivariada de dados para tomada de decisões. 6. ed. Rio de Janeiro: Elsevier, 2009.

GICO JR., Ivo Teixeira. Anarquismo judicial e teoria dos times. Economic Analysis of Law Review, v. 4, n. 2, p. 269-294, 2013.

GOMES, Adalmir Oliveira; ALVES, Simone Tiêssa; SILVA, Jéssica Traguetto. Effects of investment in information and communication technologies on productivity of courts in Brazil. Government Information Quarterly, v. 35, n. 3, p. 480-490, 2018a.

GOMES, Adalmir Oliveira; ALVES, Simone Tiêssa de Jesus; SILVA, Jéssica Traguetto. Relação entre investimento em tecnologia e produtividade de tribunais no Brasil. Relação entre investimento em tecnologia e produtividade de tribunais no Brasil. Encontro de Administração da Justiça. Anais... 2018b. 
GOMES, Adalmir Oliveira; FREITAS, Maria Eduarda Mendonça de. Correlação entre demanda, quantidade de juízes e desempenho judicial em varas da Justiça Federal no Brasil. Revista Direito GV, v. 13, n. 2, p. 567$-585,2017$.

GOMES, Adalmir Oliveira; GUIMARÃES, Tomás de Aquino. Desempenho no Judiciário: conceituação, estado da arte e agenda de pesquisa. Revista de Administração Pública, v. 47, n. 2, p. 379-401, 2013.

GOMES, Adalmir Oliveira; GUIMARÃES, Tomás de Aquino; AKUTSU, Luiz. Court Caseload Management: The Role of Judges and Administrative Assistants. RAC - Revista de Administração Contemporânea, v. 21, n. 5, p. 648-665, 2017.

GREENE, William H. Econometrics analysis Pearson. 6. ed. Upper Saddle River, New Jersey: Pearson Prentice Hall, 2008.

INSTITUTO NACIONAL DE ESTUDOS E PESQUISAS EDUCACIONAIS ANÍSIO TEIXEIRA (INEP). Sinopse Estatística da Educação Superior 2018: notas estatísticas. Brasília: Inep, 2019. Disponível em: http://portal.inep.gov.br/basica-cens0-escolar-sinopse-sinopse. Acesso em: 10 fev. 2021.

JONSKI, Kamil; MANKOWSKI, Daniel. Is Sky The Limit? Revisiting "Exogenous Productivity of Judges” Argument. International Journal for Court Administration, v. 6, n. 2, p. 53-72, 2014.

LEWIN, Arie Y.; MOREY, Richard C.; COOK, Thomas J. Evaluating the administrative efficiency of courts. Omega, v. 10, n. 4, p. 401-411, 1982.

LOURO, Alamir Costa; SANTOS, Washington Romão; ZANQUETTO FILHO, Helio. Productivity antecedents of Brazilian courts of justice: evidence from Justiça em Números. BAR - Brazilian Administration Review, v. 14, n. 4, p. 1-18, 2017.

MITSOPOULOS, Michael; PELAGIDIS, Theodore. Does staffing affect the time to dispose cases in Greek courts? International Review of Law and Economics, v. 27, n. 2, p. 219-244, 2007.

MORA-SANGUINETTI, Juan S.; GAROUPA, Nuno. Do lawyers induce litigation? Evidence from Spain, 2001 - 2010. International Review of Law and Economics, v. 44, n. October, p. 29-41, 2015.

MOURA, Ana Raira V.; COSTA, Jamille Coutinho; MENDONÇA, Thaynara da Silva. Fatores inversamente proporcionais: maior número de faculdades de direito menor alcance de qualidade na educação. VI Colóquio Internacional "Educação e Contemporaneidade”. Anais... São Cristóvão-SE/Brasil: 2012.

NOGUEIRA, José Marcelo Maia et al. Estudo exploratório da eficiência dos tribunais de justiça estaduais 
brasileiros usando a Análise Envoltória de Dados (DEA). Revista de Administração Pública, v. 46, n. 5, p. 1317-1340, 2012.

PROCOPIUCK, Mario. Information technology and time of judgment in specialized courts: what is the impact of changing from physical to electronic processing? Government Information Quarterly, v. 35, n. 3, p. 491-501, 2018.

RIBEIRO, Ludmila. A Emenda Constitucional 45 e a questão do acesso à Justiça. Revista Direito GV, v. 4, n. 2, p. 465-492, 2008.

ROSALES-LÓPEZ, Virginia. Economics of court performance: an empirical analysis. European Journal of Law and Economics, v. 25, n. 3, p. 231-251, 2008.

SADEK, Maria Tereza. Judiciário: mudanças e reformas. Estudos Avançados, v. 18, n. 51, p. 79-101, $2004 a$.

SADEK, Maria Tereza Aina. Poder Judiciário: perspectivas de reforma. Opinião Pública, v. 10, n. 1, p. 1-62, 2004b.

SÁTIRO, Renato Máximo. Determinantes emergentes da produtividade em tribunais de justiça estaduais. 2019. Dissertação (Mestrado em Administração) - Faculdade de Administração, Ciências Contábeis e Ciências Econômicas - FACE. Programa de Pós-Graduação em Administração, Universidade Federal de Goiás (UFG), Goiânia, 2019.

SAUERBRONN, Fernanda Filgueiras; SAUERBRONN, João Felipe Rammelt. Representações sociais da reforma do Judiciário - um estudo baseado nas perspectivas dos servidores do Tribunal de Justiça do Estado da Bahia. Revista de Administração Pública, v. 49, n. 3, p. 719-737, 2015.

SOUSA, Marcos de Moraes; GUIMARÃES, Tomás de Aquino. Resources, innovation and performance in labor courts in Brazil. Revista de Administração Pública, v. 52, n. 3, p. 486-506, 2018.

VASCONCELOS, Caio Castelliano de; WATANABE, Eduardo; NETTO, Waldir Leôncio. The Impact of Attorneys on Judicial Decisions: Empirical Evidence from Civil Cases. International Journal for Court Administration, v. 9, n. 2, 2018.

VERONESE, Alexandre. Projetos judiciários de acesso à justiça: entre assistência social e serviços legais. Revista Direito GV, v. 3, n. 1, p. 13-34, 2007.

VIEIRA, Luciano José Martins; PINHEIRO, Ivan Antônio. Contribuições do Conselho Nacional de Justiça para a gestão do Poder Judiciário. XXXII EnANPAD, 6 a 10 de setembro, 2008. 
VOIGT, Stefan. Determinants of judicial efficiency: a survey. European Journal of Law and Economics, v. 42, n. 2, p. 183-208, 2016.

VOIGT, Stefan; EL-BIALY, Nora. Identifying the determinants of aggregate judicial performance: taxpayers' money well spent? European Journal of Law and Economics, v. 41, n. 2, p. 283-319, 2016.

YEUNG, Luciana Luk-Tai; AZEVEDO, Paulo Furquim de. Além dos “achismos” e das evidências anedóticas: medindo a eficiência dos tribunais brasileiros. Economia Aplicada, v. 16, n. 4, p. 643-663, 2012. 


\section{APÊNDICE METODOLÓGICO}

\section{ANÁLISE DE PRESSUPOSTOS E ESCOLHA DO MELHOR MODELO DE ESTIMAÇÃO DE DADOS EM PAINEL}

\section{ANÁlise dOS PRESSUPOSTOS}

A técnica de Regressão Múltipla com dados em painel implica a necessidade de se cercar de alguns cuidados quando de sua aplicação, e um desses indicadores está relacionado à verificação da normalidade na distribuição dos resíduos.

Foi realizado o teste de Jarque Bera a fim de verificar se os erros seguem uma distribuição normal. Esse teste compara o formato da distribuição dos erros com o formato da distribuição de uma curva normal (BAIGORRI, 2014).

A estatística obtida por intermédio do teste de Jarque Bera confirma a não normalidade da distribuição. $\mathrm{O}$ p-valor associado (p-valor: 0,12 ) não é estatisticamente significante, motivo pelo qual se pode rejeitar a hipótese nula de distribuição normal dos resíduos e conclui-se pela não normalidade da distribuição deles, não atendendo, portanto, ao pressuposto em questão.

Em relação à violação do pressuposto da normalidade dos resíduos, observa-se que ela decorre da própria estrutura dos dados. Por mais que se busque realizar a suavização das discrepâncias entre os TJs, por meio do citado método de divisão dos valores das demais variáveis pelo número de magistrados de determinado tribunal, observou-se que uma grande parte da variabilidade e amplitude dos valores assumidos por cada variável não desapareceu. Tal amplitude acaba por exercer influência sobre os resíduos observados, tornando-os, para o modelo em questão, não normais.

Apesar de rejeitada a hipótese de normalidade dos erros, isso não invalida o modelo utilizado no presente trabalho (BAIGORRI, 2014), pois, segundo o Teorema do Limite Central, quando a distribuição da população não apresenta distribuição normal, a distribuição da média dos dados converge para a distribuição normal conforme o tamanho da amostra aumenta (BROOKS, 2014).

O segundo pressuposto a ser considerado diz respeito à correlação que os termos de erro podem apresentar com uma ou mais variáveis explicativas, haja vista a possibilidade de assumirem valores positivos ou negativos. No caso de existir tal correlação, considera-se que cada termo de erro não possui a mesma probabilidade de assumir valores positivos ou negativos, gerando o problema da heterocedasticidade dos resíduos (FÁVERO et al., 2009).

No intuito de realizar a operacionalização do teste relativo à homocedasticidade dos resíduos, foi realizado o teste de Wald. O p-valor obtido (p-valor: 2,00087e-012) permite concluir pela rejeição da hipótese de que os resíduos são homocedásticos, não atendendo, portanto, ao pressuposto em questão. 
A despeito de tal constatação, observa-se que, na presença de heterocedasticidade, os estimadores associados ao modelo de Efeitos Fixos ainda seriam não viesados e consistentes, mas considera-se que eles não serão mais eficientes (GREENE, 2008).

O terceiro pressuposto é a ausência de autocorreção entre os termos do erro. Salienta-se que tal verificação deve ser elaborada para modelos de regressão que apresentam um componente temporal associado, haja vista o fato de que a autocorrelação deve ser elaborada com base em dois termos de erro subsequentes e que modelos de regressão que apresentam uma ordem temporal não permitem que haja mudança na ordem das observações (FÁVERO et al., 2009).

Foi realizado o teste de Durbin-Watson, encontrando um p-valor de 0,0002 (estatística de Durbin-Watson $=1,5146)$. Esse valor permite concluir pela rejeição da hipótese de que os resíduos são aleatórios, ou seja, não atendendo ao pressuposto em questão.

Outro ponto a se considerar em relação ao modelo de Regressão Múltipla com dados em painel diz respeito à ausência de multicolinearidade. Com a inclusão de muitas variáveis explicativas em um modelo, pode ocorrer que duas ou mais variáveis apresentem comportamentos semelhantes, existindo elevada correlação entre elas (FÁVERO et al., 2009).

Uma estatística muito utilizada para a elaboração do diagnóstico de multicolinearidade em modelos de regressão é a estatística Variance Inflation Factor (VIF), que indica a medida de variação de cada coeficiente de regressão estimado devido à multicolinearidade (FÁVERO et al., 2009).

Por intermédio do teste VIF realizado, observa-se que não há valores maiores que 5, portanto não há variáveis com alta correlação entre si - e que desse modo estariam explicando parte semelhante da variável dependente.

\section{ESCOLHA DO MELHOR MODELO DE ESTIMAÇÃO DE DADOS EM PAINEL}

No intuito de identificar o melhor modelo de análise de dados em painel, fez-se necessária a realização de uma sequência dos testes estatísticos.

$\mathrm{O}$ primeiro teste realizado foi o Teste $\mathrm{F}$ de significância conjunta da diferenciação das médias de grupo; tal teste fornece uma estatística que possibilita a escolha entre o modelo Pooled e o modelo de Efeitos Fixos. Com base no p-valor obtido (p-valor: 7,93236e-029), é possível rejeitar a hipótese nula de que o modelo Pooled é adequado para a investigação proposta no presente trabalho, concluindo pela existência de efeitos fixos.

O segundo teste realizado foi o Teste de Breusch Pagan, de modo a possibilitar a escolha entre o modelo Pooled e o modelo de Efeitos Aleatórios. A hipótese nula de tal teste assume que os erros são normalmente distribuídos. Desse modo, em virtude de o p-valor (p-value: 4,89759e-019) ser menor que o nível de significância, conclui-se pela rejeição da hipótese nula, corroborando a utilização do Modelo de Efeitos Aleatórios como o mais adequado à realização da Regressão Múltipla pretendida pelo presente trabalho, em comparação com o modelo Pooled. 
Conforme as conclusões obtidas nos testes anteriores, pode-se argumentar a existência de Efeitos Fixos e Efeitos Aleatórios associados ao modelo proposto. O seguinte passo foi a realização do teste de Hausman, de modo a possibilitar a escolha entre o modelo de Efeitos Fixos e o modelo de Efeitos Aleatórios. O teste de Hausman define se existe diferença estatisticamente significante entre os estimadores obtidos pelos dois modelos. Desse modo, pela probabilidade obtida (p-value $=4,72299 \mathrm{e}-008$ ), rejeita-se a hipótese nula de que não existe correlação entre os componentes de erro e os componentes obtidos, corroborando o modelo de Efeitos Fixos como o mais adequado para a estimação do modelo proposto pelo presente trabalho.

A Tabela 4 evidencia a especificação dos testes, com um resumo acerca dos objetivos, dos testes, das hipóteses e das conclusões sobre cada um dos testes realizados.

TABELA 4 - ESPECIFICAÇÃO DOS TESTES

\begin{tabular}{|c|c|c|c|c|}
\hline OBJETIVO & TESTE & HIPÓTESE NULA & ESTATÍSTICA & CONCLUSÃO \\
\hline FORMA POOLEDX & TESTE F & HO: FORMA POOLED & P-VALOR: & EFEITOS FIXOS \\
\hline EFEITOS FIXOS & & É ADEQUADA & $7,93236 \mathrm{E}-029$ & É ADEQUADO \\
\hline FORMA POOLEDX & TESTE DE & HO: FORMA POOLED & P-VALOR: & EFEITOS ALEATÓRIOS \\
\hline EFEITOS ALEATÓRIOS & BREUSCH PAGAN & É ADEQUADA & 4,89759E-019 & É ADEQUADO \\
\hline EFEITOS FIXOS $x$ & TESTE DE & HO: MODELO DE EFEITOS & P-VALOR: & EFEITOS FIXOS \\
\hline EFEITOS ALEATÓRIOS & HAUSMAN & ALEATÓRIOS É ADEQUADO & 4,72299E-008 & É ADEQUADO \\
\hline
\end{tabular}

Fonte: Elaborada pelos autores.

\section{COMO CITAR ESTE ARTIGO:}

SÁTIRO, Renato Máximo; SOUSA, Marcos de Moraes. Determinantes quantitativos do desempenho judicial: fatores associados à produtividade dos tribunais de justiça. Revista Direito GV, v. 17, n. 1, jan./abr. 2021, e2107. https:// doi.org/10.1590/2317-6172202107
Renato Máximo Sátiro

Mestre em Administração pela Universidade Federal de Golás (UFG). Doutorando em Administração no Programa de Pós-Graduação em Administração da UFG. renato_maximo_satirolufg.br r.maximo.satirolahotmail.com

Marcos de Moraes Sousa

Doutor em Administração Pela Universidade de Brasília (UnB).

Professor Permanente no Programa de Pós-graduaC̣ão EM Administração da Universidade Federal de GoIas (PPGADM-UFG). Professor permanente no Programa de Pós-graduação em Educação Profissional e TeCnológica (ProfePT-IFGOIANO).

marcos.moraeslaifgoiano.edu.br 